\title{
Rationale for therapeutic decision-making in locally advanced and metastatic radioactive iodine (RAI)- refractory differentiated thyroid cancer, starting from a clinical case
}

\author{
Cristina Alina Silaghi ${ }^{1,2}$, Oana Stãnoiu-Pînzariu ${ }^{1,}$, , Horaţiu Silaghi ${ }^{3}$, Doina Piciu ${ }^{4}$, \\ Carmen Emanuela Georgescu ${ }^{1,2}$
}

1Department of Endocrinology, "luliu Haţieganu" University of Medicine and Pharmacy Cluj-Napoca; ${ }^{2}$ Endocrinology Clinical Unit, Cluj County Emergency Hospital, Cluj-Napoca, Romania; ${ }^{3}$ Department of Surgery V, "luliu Haţieganu" University of Medicine and Pharmacy Cluj-Napoca; ${ }^{4}$ Nuclear Medicine Clinical Unit, Institute of Oncology Cluj-Napoca, Romania

\begin{abstract}
lodine uptake and organification are the hallmarks of thyroid cells differentiation. The loss of these characteristics in thyroid cancer leads to radioactive iodine refractoriness, a rare condition that bears a low survival rate and poor prognosis. We present a 52-year-old patient presenting dry cough and dyspnea in the supine position. Imaging examinations revealed a thyroid nodule with a high suspicion of malignancy in the right thyroid lobe, multiple laterocervical and mediastinal lymph nodes, lung, bone, and brain metastases. Fine needle aspiration cytologic features have advocated for papillary thyroid cancer (PTC). The patient underwent total thyroidectomy and selective lymphadenectomy. Subsequently, the patient received suppressive treatment with levothyroxine and four courses of radioactive iodine therapy. In addition, to treat bone and brain metastases, the patient experienced external radiotherapy and glucocorticoid therapy. Despite this rigorous therapeutic management, the patient obtained an incomplete structural and functional response. Although the last two posttherapeutic ${ }^{131}$ I whole-body scans were negative, the patient had elevated stimulated thyroglobulin levels and loco-regional recurrence by thyroid ultrasound. This aspect would suggest that thyroid cells become unable to uptake ${ }^{131}$, most likely through the emergence of new genetic mutations in the cancer cells. In conclusion, our patient's case suggests a ${ }^{131}$-refractory PTC, requiring the initiation of novel targeted systemic agents such as tyrosine kinase inhibitors, in order to improve structural and functional outcomes of radioactive iodine therapy and to afford prolonged progression-free survival advantage.
\end{abstract}

Keywords: papillary thyroid cancer; radioactive iodine-refractory; differentiated thyroid cancer; sodium/iodide symporter; tyrosine kinase inhibitor; brain metastasis

\section{Introduction}

Papillary thyroid carcinoma (PTC) is characterized by a high survival rate and a low

Received: October 2021; Accepted after review: December 2021; Published: December 2021.

*Corresponding author: Oana Stãnoiu-Pînzariu, Department of Endocrinology, "Iuliu Haţieganu" University of Medicine and Pharmacy Cluj-Napoca, Romania.

Email: oana pinzariu@yahoo.com incidence of distant metastases, being considered the most common type of thyroid cancer (TC). Along with follicular thyroid cancer (FTC), PTC is part of differentiated thyroid cancer (DTC) [1].

An extensive body of literature shows that DTCs are slow-progressing tumors proving a very good prognosis, with an overall survival (OS) of 20 years greater than $90 \%$ with conventional treatment, i.e., combination of total thyroidectomy, resection of loco-regional 
metastases, radioactive iodine (RAI) and thyroid hormone suppression [2]. However, a subgroup of patients with DTC may be characterized by a more aggressive progression of the disease and develops recurrent or metastatic disease and is refractory to radioactive iodine therapy (RAIrefractory DTC) showing a decreased 10-year survival rate to $15-20 \%$ de [3]. In line with the American Thyroid Association (ATA) guideline, the diagnostic criteria for RAl-refractory DTC are as follows: (1) disease without RAI uptake or (2) loss of RAI uptake ability after initial adequate uptake, (3) progressive disease despite appropriate RAl uptake, and (4) RAI uptake in some lesions associated with no uptake in others [1]. Herein we report the clinical, pathological, and imagistic findings of a patient with PTC and simultaneous multiple metastases, including a solitary cerebral metastasis. Brain metastases (BM) from PTC are uncommon but carry a poor prognosis [4]. This patient depicted gradually a RAIrefractory DTC, that goes with a reduced survival rate. Thus, the patient is a good candidate for new targeted therapies.

Age over 40 years, extended lesions and metastases showing increased fluorodeoxyglucose (FDG) uptake on position emission tomography (PET) could be important factors to influence the refractoriness of the RAI. Towards the end of this case presentation, we will discuss possible therapeutic directions for this patient. Lenvatinib and Sorafenib, two new tyrosine kinase inhibitors (TKIs), have promoted a novel, hopeful systemic therapeutic option for metastatic RAI-refractory DTC [5]. It appears that TKI would also play a neoadjuvant role in selected cases of locally advanced DTC to decrease tumor volume in order to facilitate surgical resection and decrease perioperative morbidity [6].

\section{Case report}

A 52-year-old female patient, known with grade 1 hypertension, was admitted to the Endocrinology Clinic with persistent dry cough and feeling of suffocation in the supine position. Physical examination revealed an enlarged thyroid gland, with renitent consistency, preserved mobility, and no sensitivity or pain to palpation. Laboratory tests indicated mild hyperglycemia $(111 \mathrm{mg} / \mathrm{dl})$ and calcitonin $(5.39 \mathrm{pg} / \mathrm{ml}$, normal range: 0 $11.5 \mathrm{pg} / \mathrm{ml}$ ) within normal limits. Thyroid hormone profile showed euthyroidism $(\mathrm{TSH}=1.87 \mu \mathrm{Ul} / \mathrm{ml}$, normal range: $0.4-4$ $\mu \mathrm{Ul} / \mathrm{ml}$; FT4=0.66 ng/dl, normal range: 0.61 $1.35 \mathrm{ng} / \mathrm{dl}$ ). The thyroid ultrasound (TUS) described an enlargement of the thyroid gland (total volume of $27.46 \mathrm{ml}$ ) and a partially echoic, partially anechoic nodular formation in the left thyroid lobe (LTL), measuring $1.7 / 1.5 / 1.43 \mathrm{~cm}$. In the middle third of the right thyroid lobe (RTL), a hypoechoic, inhomogeneous nodule with coarse calcifications was detected, measuring $3.38 / 2.1 / 1.8 \mathrm{~cm}$ (Figure 1).

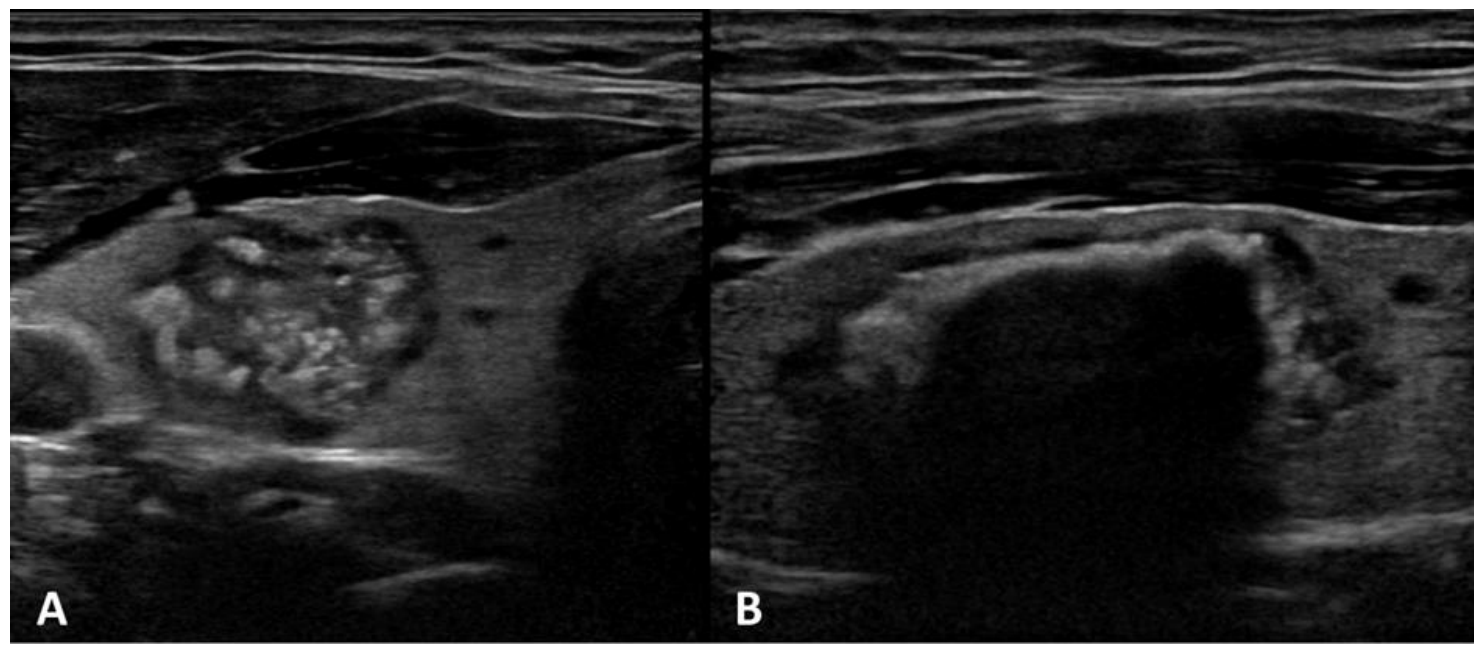

Fig. 1. Thyroid ultrasound - transverse (A) and longitudinal $(B)$ section: a hypoechoic, inhomogeneous nodule with coarse calcifications in the middle third of the right thyroid lobe, measuring $3.38 / 2.1 / 1.8 \mathrm{~cm}$ 
In addition, the TUS identified three lymph nodes near the isthmus and at the lower pole of the RTL, measuring between 2 and $3 \mathrm{~cm}$.

Neck and chest CT scan confirmed the presence of hypodense nodules, some with coarse calcifications in both thyroid lobes and isthmus (Figure 2). CT scan also described multiple laterocervical and mediastinal lymph nodes, but also calcareous pulmonary micronodules suggestive of distant metastases (Figures 2 and 3 ).

The fine needle aspiration (FNA) of the suspicious nodular formation in the RTL was performed. The FNA cytology identified papillary cell structures with moderate cytonuclear atypia, psammoma bodies, and giant multicellular cells (Bethesda VI).
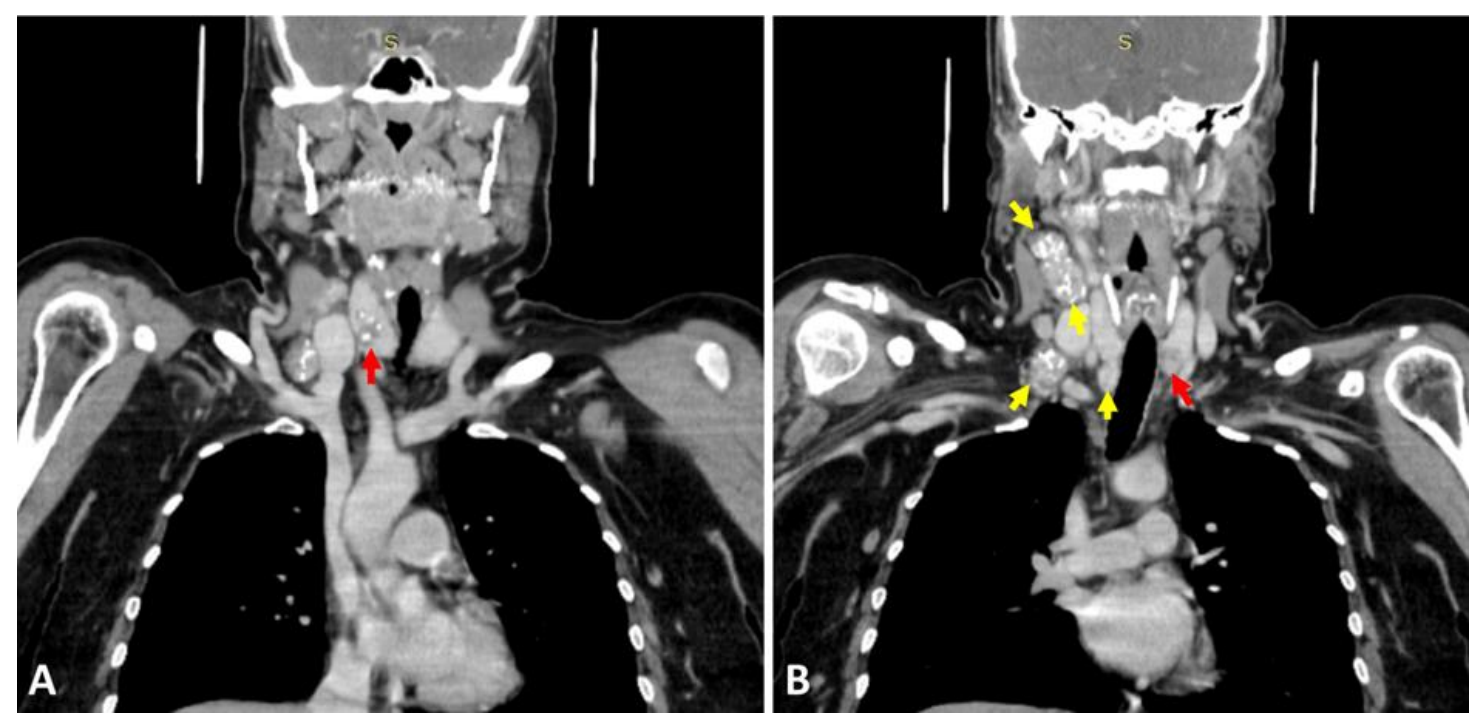

Fig. 2. Coronal neck and chest CT scan: $(A)$ hypodense nodule with coarse calcifications the middle third of the right thyroid lobe (red arrow); (B) hypodense nodular formation in the left thyroid lobe (red arrow), multiple laterocervical lymph nodules (yellow arrows)

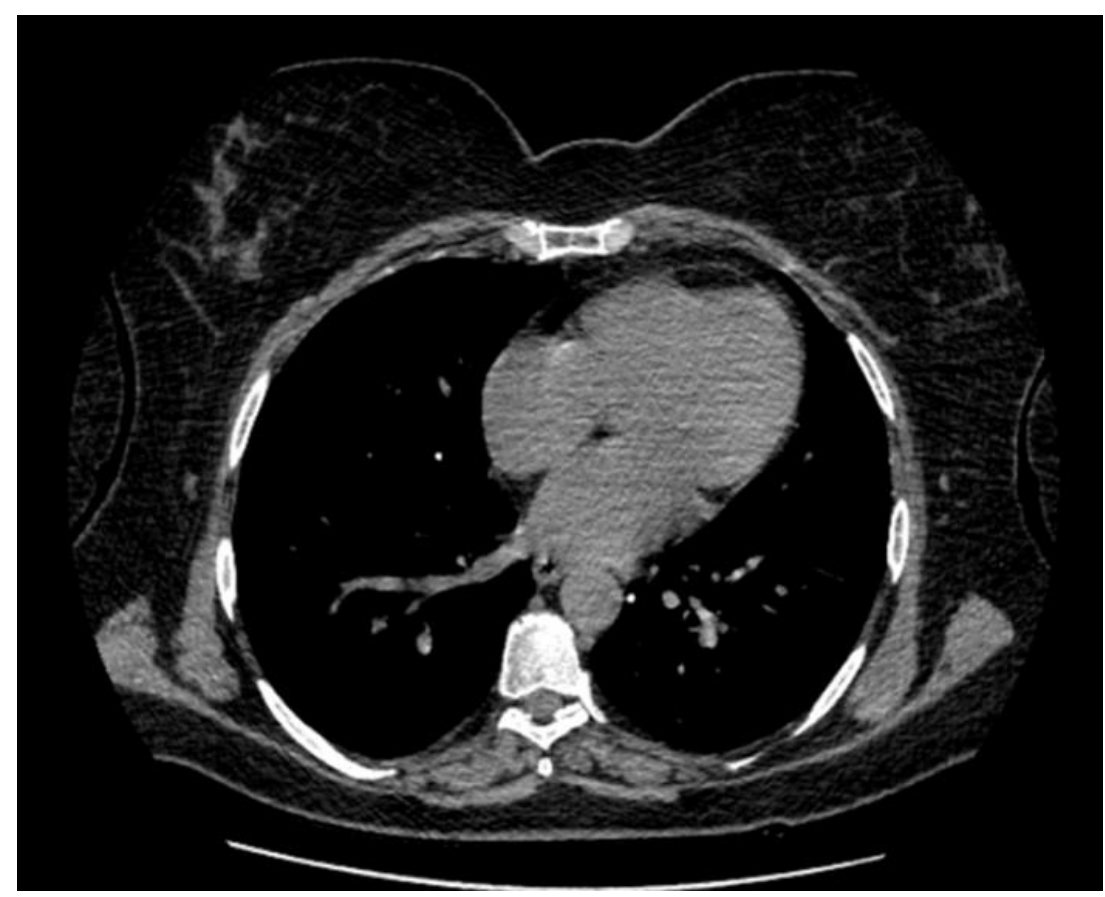

Fig. 3. Axial CT scan of the chest: pulmonary micronodules suggestive of lung metastases measuring a maximum of $0.4 \mathrm{~cm}$ 
Considering the clinical, imaging, and histopathological data, surgery was recommended. Thus, the patient underwent total thyroidectomy and selective lymphadenectomy.

Postoperative macroscopic examination of the thyroid brought out that both lobes and the isthmus were affected by a whitish tumor process with calcified areas. Microscopic examination unveiled that both thyroid lobes and the isthmus were infiltrated with tumor nodules with the characteristics of PTC. The tumor infiltration, extending to the edge of the
LTL, contained conjunctival and calcified areas and associated lymphatic invasion. The mitotic index was 1/10 HPF. The non-tumor thyroid parenchyma contained adenomatous thyroid nodules. Of the 14 lymph nodes examined, eleven showed metastases. The pathological diagnosis was $\mathrm{pT} 3(\mathrm{~m}), \mathrm{N} 1 \mathrm{~b}, \mathrm{M} 1, \mathrm{~L} 1, \mathrm{~V} 0, \mathrm{R} 1$.

The patient required radioactive iodine therapy (RAIT) (dose of $3.08 \mathrm{GBq}$ ), given the postoperative persistence of thyroid tissue and right laterocervical lymph nodes, corroborated with stimulated thyroglobulin (stim-Tg) of 334.7 $\mathrm{ng} / \mathrm{ml}$ (Figure 4).

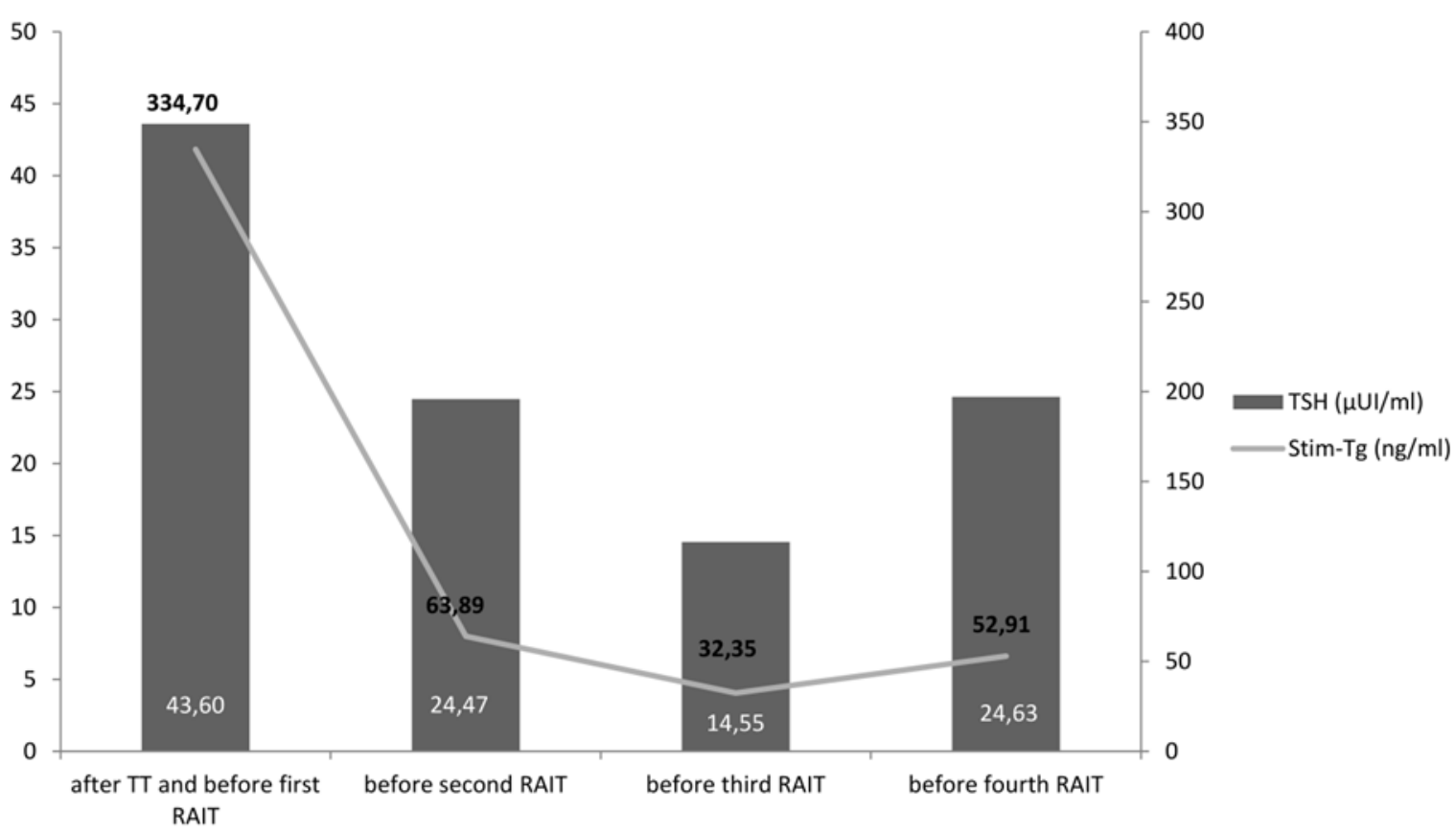

Fig. 4. The evolution of stimulated thyroglobulin in long-term monitoring. TT: total thyroidectomy; RAIT: radioactive iodine therapy; stim-Tg: stimulated thyroglobulin; $\mathrm{TSH}$ : thyroid stimulating hormone; normal range values for stim-Tg $(<1 \mathrm{ng} / \mathrm{ml})$ and TSH after discontinuation of levothyroxine $(>30 \mu \mathrm{Ul} / \mathrm{ml})$

Posttherapeutic ${ }^{131}$ I whole-body scan (WBS) detected residual tissue in the thyroid lodge and right laterocervical and retrosternal lymph nodes. In addition, WBS showed a pathological uptake of ${ }^{131}$ I in the left parietal bone and bilateral multiple lung nodules (Table I).

The cranial CT scan described an osteolytic lesion in the left parietal bone, with the significance of distant metastasis. More than that, the brain MRI detected a focal lesion hyperintense in T1 and T1-MPRAGE in the frontal lobe of $1.2 / 0.8 \mathrm{~cm}$, with perilesional edema $(3.5 / 4.3 \mathrm{~cm})$, with the significance of brain metastasis (Figure 5). For these two craniocerebral lesions, the patient underwent palliative external radiotherapy (dose of $30 \mathrm{~Gy}$ in ten fractions for 14 days) and corticotherapy (Medrol $16 \mathrm{mg} /$ day).

Subsequently, the patient was evaluated periodically every three months, following suppressive treatment with levothyroxine in doses between 150 and $175 \mu \mathrm{g} /$ day. 
Table I. Posttherapeutic ${ }^{131}$ I whole-body scan after multiple courses of radioactive iodine therapy

131I dose

(GBq)

\begin{tabular}{c|c|c|}
\hline $\begin{array}{c}\text { First } \\
\text { RAIT }\end{array}$ & 3.08 & $\begin{array}{c}\text { residual tissue in the thyroid lodge; } \\
\text { right laterocervical and retrosternal lymph nodes; pathological uptake of }{ }^{131} \text { I in the left } \\
\text { parietal bone and bilateral multiple lung nodules }\end{array}$ \\
$\begin{array}{c}\text { Second } \\
\text { RAIT }\end{array}$ & 3.99 & residual tissue in the thyroid lodge; pathological uptake of ${ }^{131}$ I in bilateral lung areas, but \\
clearly improved
\end{tabular}

RAIT: radioactive iodine therapy; WBS: whole-body scan

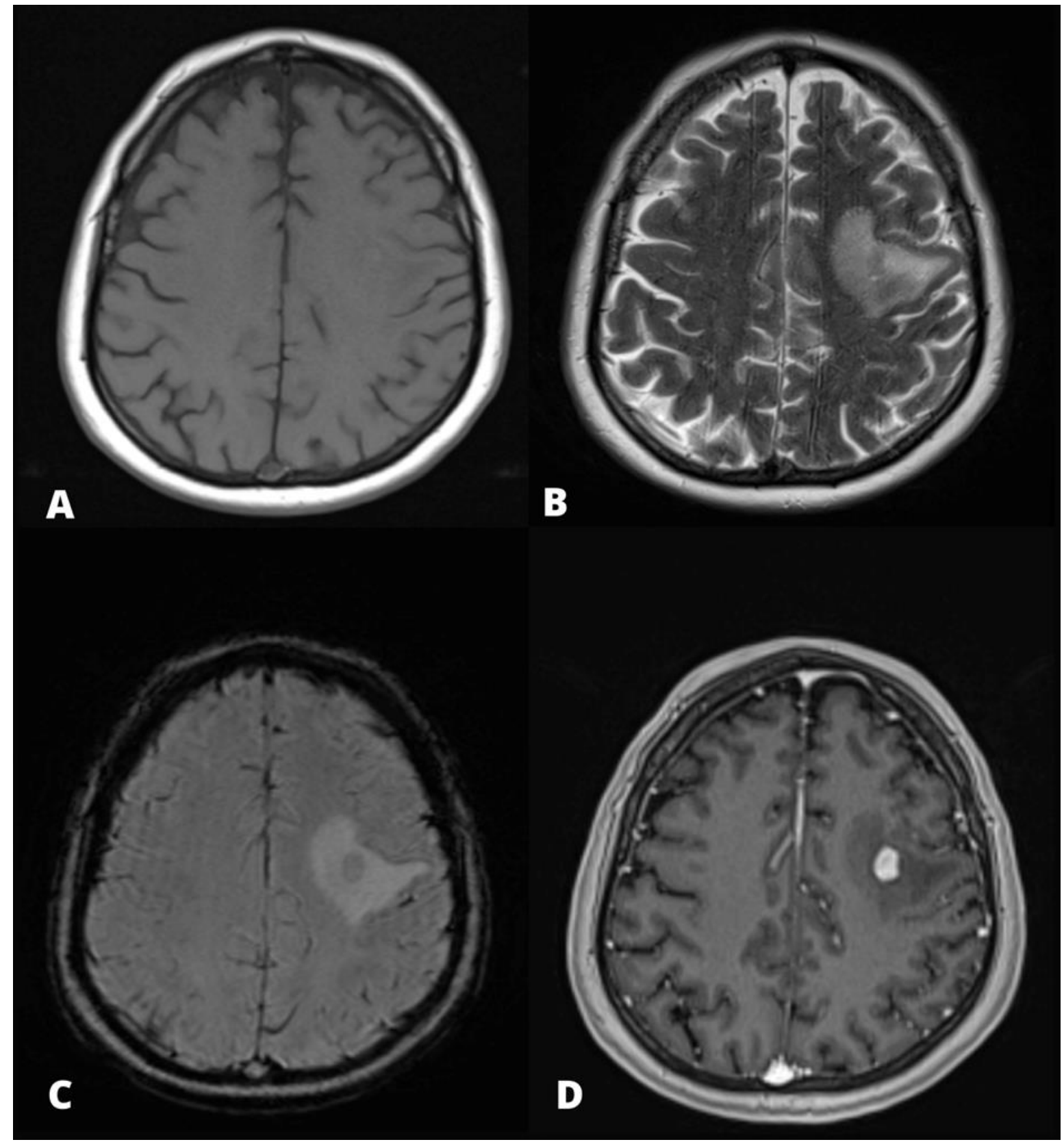

Fig. 5. Axial brain MRI - (A) T1, (B) T2, (C) SWI and (D) T1-MPRAGE images: focal lesion in the frontal lobe of $1.2 / 0.8 \mathrm{~cm}$, with perilesional edema extended over an area of $3.5 / 4.3 \mathrm{~cm}$. 
Six months after the first RAIT, the patient had stim- $\mathrm{Tg}$ of $63.89 \mathrm{ng} / \mathrm{ml}$, associated with presence of thyroid tissues in the thyroid lodge and the bilateral laterocervical areas on TUS. Thus, the patient underwent the second RAIT (dose of $3.99 \mathrm{GBq}$ ). Posttherapeutic ${ }^{131}$ I WBS showed residual tissue in the thyroid lodge and pathological uptake of the radiotracer in bilateral lung areas, but clearly improved (Table I).

Three months after performing the second RAIT, TUS indicated a residual tissue, with calcifications, in the right thyroid lodge of $1.2 / 0.67 \mathrm{~cm}$. Two lymph nodes were detected in the right supraclavicular (approximately 1 $\mathrm{cm})$ and the pretracheal area $(0.76 / 0.52 \mathrm{~cm})$.
Due to the persistence of the disease, FDGPET was required. FDG-PET scan showed right multiple laterocervical, submandibular and supraclavicular lymph nodes, with intense uptake of FDG (Figure 6). Also, PET scan showed multiple lung micronodules with no FDG uptake, but raising the suspicion of metastases.

Three months later the third RAIT was required (dose of $3.39 \mathrm{GBq}$ ). The decision was based on the biochemical (stim-Tg of 32.35 $\mathrm{ng} / \mathrm{ml}$ ) and imaging persistence of the disease. Posttherapeutic ${ }^{131}$ | WBS showed no residual tissue in the thyroid lodge and the absence of radiotracer uptake in the cervical area or distant organs (Table I).

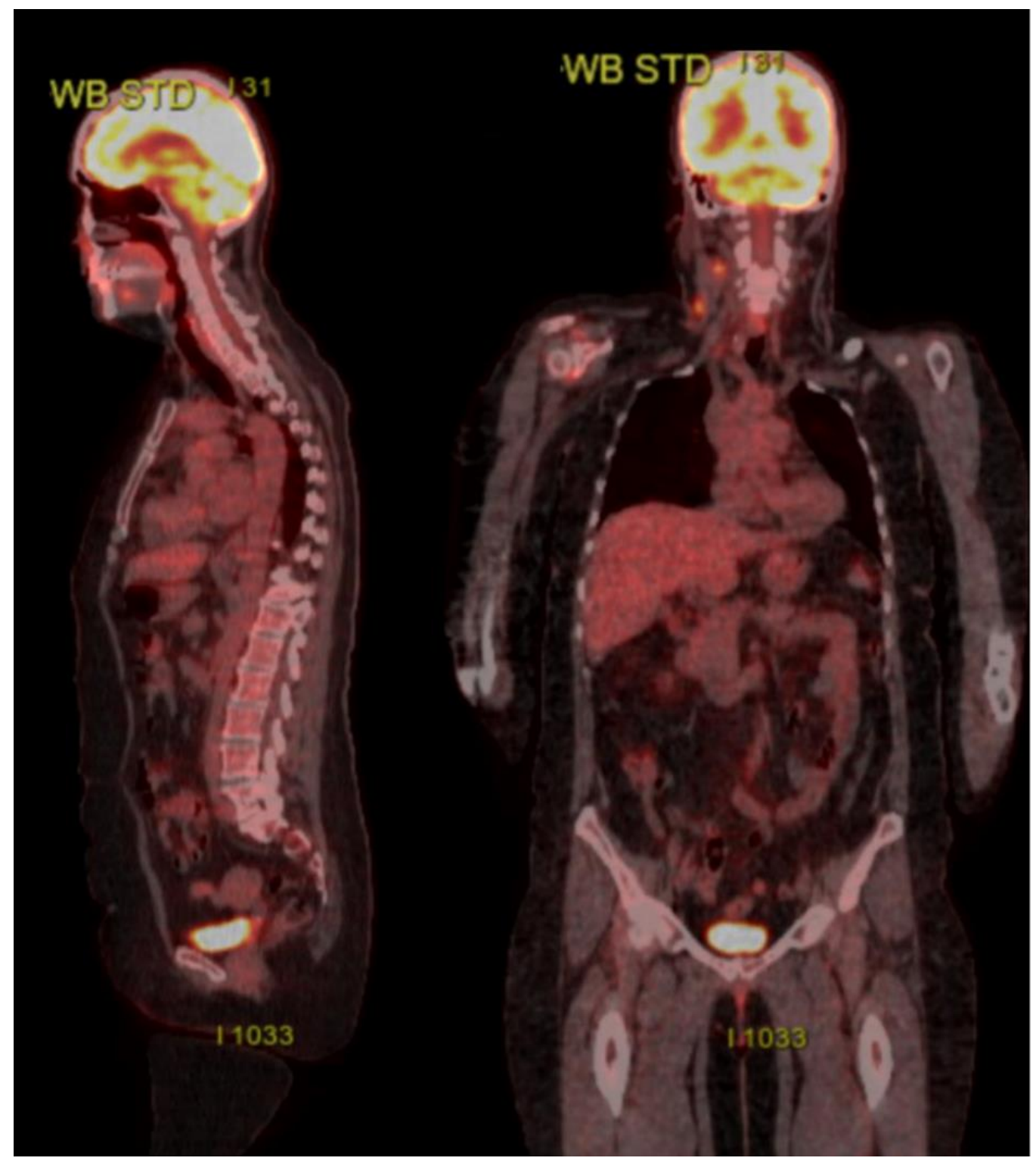

Fig. 6. Sagittal and coronal FDG-PET images: right multiple laterocervical, submandibular and supraclavicular lymph nodes, with intense uptake of FDG 
Three months after the last RAIT, despite appropriate suppression of TSH $(0.01 \mu \mathrm{UI} / \mathrm{ml})$ under treatment with levothyroxine 150 $\mu \mathrm{g} /$ day, imaging examinations certified the persistence of the disease. Thus, the TUS described in the right thyroid lodge two hypoechoic areas, with calcifications, measuring $1.4 \mathrm{~cm}$ and $1.43 \mathrm{~cm}$, respectively. In the left thyroid lodge, in the area of the infrahyoid muscles, three formations were described (up to $6.2 \mathrm{~mm}$ ). In addition, multiple lymph nodes, measuring up to $1 \mathrm{~cm}$, were detected at the sternal manubrium, in the right laterocervical area and the left pretracheal area (Figure 7) and the stim- $\mathrm{Tg}$ value was higher $(52.91 \mathrm{ng} / \mathrm{ml})$ than the previous one (Table I). Thus, the patient underwent the fourth course of RAIT (dose of $4.75 \mathrm{GBq}$ ). Posttherapeutic ${ }^{131}$ I WBS showed no residual tissue in the thyroid lodge and the absence of radiotracer uptake in the cervical area or distant organs (Table I, Figure 8).

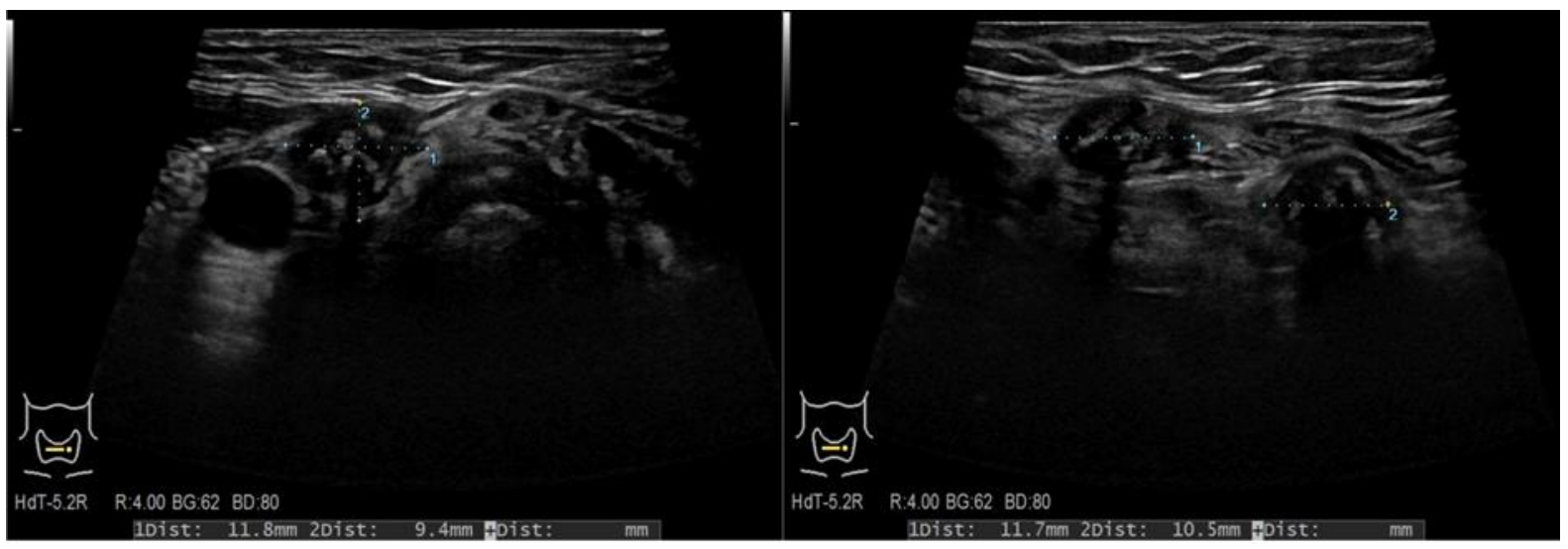

Fig. 7. Thyroid ultrasound: transverse and longitudinal section: two lymph nodes with coarse calcifications in the right thyroid lodge, measuring $1.18 / 0.94 / 1.17 \mathrm{~cm}$ and $1.05 \mathrm{~cm}$ respectively

\section{Discussion}

In our case, the final diagnosis was highrisk PTC, with loco-regional and distant metastases (lung, brain, and bone metastases), requiring surgery, multiple courses of RAIT and thyroid hormone suppressive treatment. As it is known, RAIT is the routinely recommended as adjuvant treatment in high-risk PTC after total thyroidectomy [1]. The main goal of RAIT is to ablate the postoperative remnant thyroid tissue and eliminate the loco-regional and distant micrometastases [7]. ${ }^{131}$ I dose used for the ablative purpose is up to $150 \mathrm{mCi}$ (5.5 $\mathrm{GBq}$ ) [1]. However, the ATA guidelines noticed that the benefits of a dose higher than 150 $\mathrm{mCi}$ of ${ }^{131} \mathrm{I}$ in reducing the structural recurrence of PTC in stage T3 or N1 is uncertain [1]. Despite the combined therapy applied to the patient exposed here, an incomplete structural and functional response has been obtained. Thus, optimal therapeutic management, in this case, should include a surgical reoperation and targeted therapies.

Our patient has PTC and simultaneous multiple metastases, including lung, bone, and cerebral (solitary). Distant metastases of PTC are rare and usually occur in the lungs and thoracic lymph nodes in addition to the common loco-regional lymph nodes. RAIT is routinely recommended for lung metastases treatment (with doses between 100 and 200 $\mathrm{mCi}$ ) and can be repeated after 6-12 months. The complete remission of lung metastases after RAIT is rare, and the prognosis remains unfavorable [1]. Brain and bone metastases in PTC are rare conditions and are associated with a poor prognosis [1, 8]. The main therapies recommended for bone metastases include surgery, external radiation and bonedirected agents [1]. However, if bone metastases have increased uptake of ${ }^{131}$, RAIT may be considered [1]. BM occur in approximately $1 \%$ of all DTC, and $4.5-18 \%$ of patients with other distant metastases $[9,10]$. 


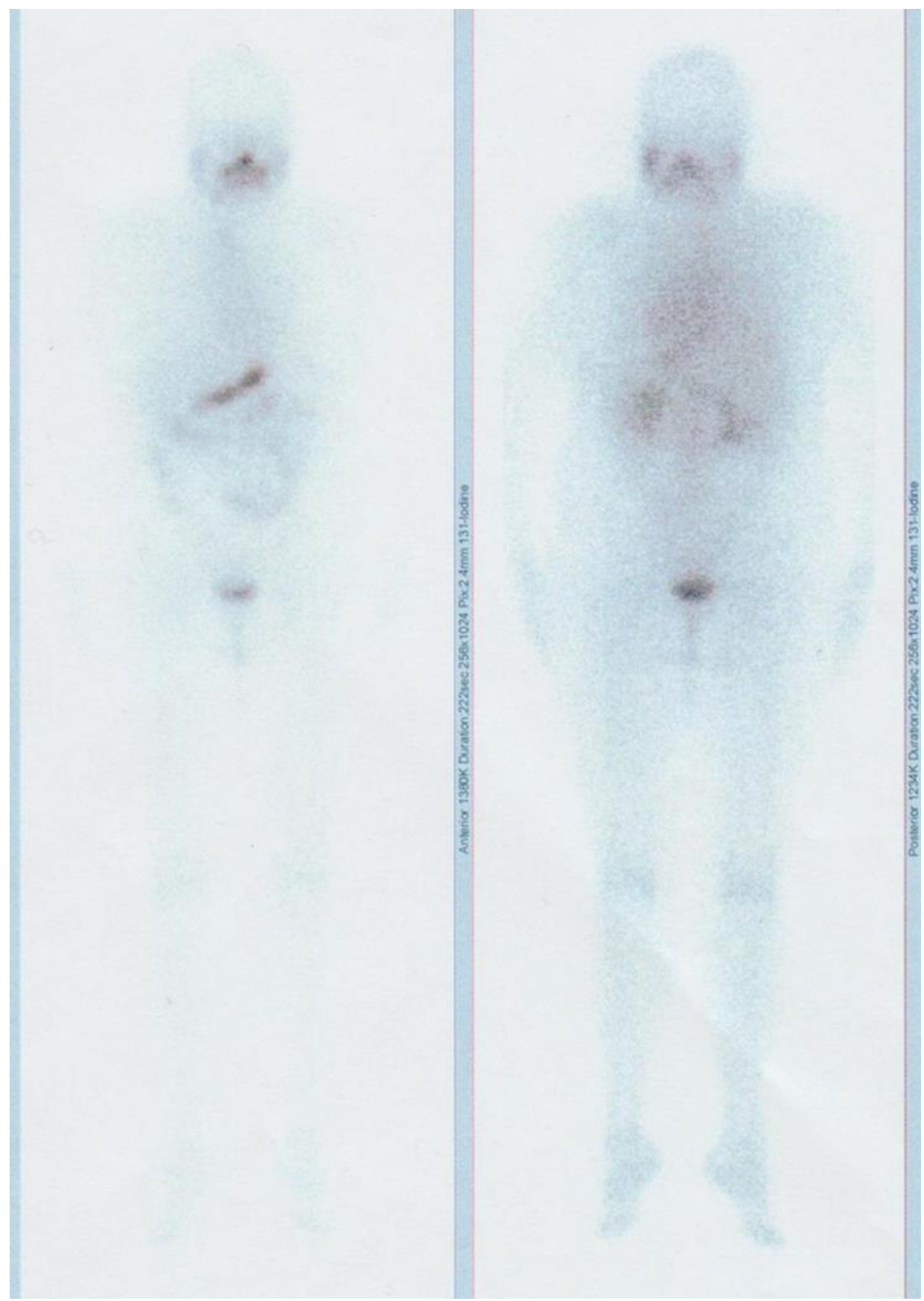

Fig. 8. Posttherapeutic ${ }^{131}$ I WBS: no residual tissue in the thyroid lodge and the absence of ${ }^{131}$ I uptake in the cervical area or distant organs

BM may be the first clinical manifestation of the disease, often leading to nonspecific symptoms, such as headaches or may develop even many years after the diagnosis of PTC [11]. Parameters that can impact OS include the time interval between the DTC/PTC and BM diagnosis, the number of BM sites, and decompressive craniectomy. It is possible that the BM in the DTC may have a gradual evolution, leading to the survival of one year, two or more years, for certain sets of patients [4]. At the same time, prognostic factors for long-term survival were defined, including the limited number of BM (less than three), BM treatment, and a Karnofsky Performance score above 70 [12, 13]. BM can be treated with surgery, external radiation or RAIT (in the case of ${ }^{131} \mathrm{I}$ avid metastases) [1]. In this last case, before performing RAIT, external radiation associated with 
corticosteroid therapy is recommended [1]. Consequently, our patient has undergone external beam radiotherapy and glucocorticoids therapy for the treatment of bone and cerebral metastases, with good subsequent clinical evolution. The presence of a single small metastasis and the rapid and complete treatment could positively influence the patient's survival.

Hirsch, et al. noted that the second RAIT did not bring significant benefits to patients with postoperative loco-regional recurrence, which was also observed in our patient [14]. Although the last two WBS were negative, our patient had elevated stim-Tg levels and locoregional recurrence by TUS. This aspect would suggest that thyroid cells become unable to uptake ${ }^{131} \mathrm{I}$, most likely through the appearance of genetic mutations in the cancer cells such as BRAF, RAS, RET, or others [15, 16].

A new course of RAIT is not appropriate for our patient, given the resistance to ${ }^{131}$ I and the theoretical possibility of long-term secondary malignancies. Although no longterm secondary malignancies were observed after one course of RAIT, the risk of secondary malignancies was correlated with the cumulative dose of ${ }^{131}$ I (>500-600 mCi) [1]. The cumulative dose of ${ }^{131} \mathrm{I}$ received by our patient was $15.21 \mathrm{GBq}(410.67 \mathrm{mCi})$. However, it appears that young patients $(<45$ years) treated with doses above $100 \mathrm{mCi}$ of ${ }^{131}$ I for PTC have a higher risk of leukemia [17, 18]. Thus, the risk of a secondary malignancy could be an additional reason for our patient to be a good candidate for new targeted therapies.

The main pathogenetic mechanisms underlying PTC are alterations of the mitogenactivated protein kinase (MAPK) and phosphoinositide 3-kinase (PI3K) pathways [15]. These two signaling pathways are regulated by the receptor tyrosine kinases (RTKs) [15]. BRAF, RET, PI3K, RAS, and PTEN are the most common incriminated mutations in altering these signaling pathways [15]. The appearance of these genetic mutations seems to generate the alteration of sodium-iodide symporter (NIS) expression, which is subsequently responsible for the decrease in the tumor cell's ability to uptake ${ }^{131}$ I $[15,19,20]$.

The further therapeutic recommendation for our patient is the introduction of tyrosine kinase inhibitors (TKIs) to target the various proteins in the PI3K and MAPK pathways. The Food and Drug Administration (FDA) has approved only two TKls for locally advanced/metastatic ${ }^{131}$-refractory DTC namely sorafenib and lenvatinib. Both drugs target platelet-derived growth factor receptor (PDGFR), vascular endothelial growth factor receptor (VEGFR) 1-3, RET, and C-KIT. Sorafenib also targets BRAF, while lenvatinib targets fibroblast growth factor receptor (FGFR) [15]. Both drugs prolong the survival rate in patients with ${ }^{131}$-refractory DTC. Therefore, in 1311-refractory DTC, treatment with sorafenib (400 mg twice per day for approximately ten months) prolonged survival rate at 10.8 months versus placebo (5.8 months) [21]. Similarly, treatment with lenvatinib (24 mg/day for approximately 17 months) prolonged survival rate in patients diagnosed with 131I-refractory DTC at 18.3 months compared with those treated with placebo (3.6 months) [22].

Although the effectiveness of these drugs is proven, their long-term use can result in resistance to TKIs [23]. Also, monitoring for possible side effects of TKIs is imperative. The most common side effects of TKIs include rash, hypertension, alopecia, diarrhea, and fatigue [15, 21].

Other TKIs appear to be effective in ${ }^{131} \mathrm{I}-$ refractory DTC, given the outcomes of several phase II and III clinical trials. These are sunitinib, vandetanib, cabozantinib, anlotinib, axitinib, pazopanib, and donafenib [15, 24-27]. Patients with DTC in whom first-line TKI treatment failed, continued to respond to cabozantinib, demonstrating that this TKI may be used as salvage therapy where there is no benefit for first-line TKls [24]. Furthermore, new therapeutical strategy using combinatorial therapy with MAPK, PI3K/AKT/mTOR, NF-kB and MTKs inhibitors, would likely improve the low therapeutic efficiency achieved with singleagent treatments in clinical trials on DTC [2830]. Regarding patients with RAI refractory DTC, they mainly present dedifferentiation of DTC. Thus, the redifferentiation treatment 
followed by RAl could represent a successful therapeutic option. Studies with PI3K and MAPK inhibitors modulating the $\mathrm{PISK} / \mathrm{AKT} / \mathrm{mTOR}$ and MAPK pathways have resulted in fluctuating results in restoring the NIS gene expression and improving the effect of RAl therapy in RAI-refractory DTC. The use of selumetinib, a MEK1/2 inhibitor [31], or dabrafenib and vemurafenib [32, 33], elective inhibitors of mutant BRAF, resulted in iodine reuptake and demonstrated some success in resensitizing tumors to RAI [34].

In the future, extensive studies will be needed to certify the potency of PI3K and MAPK inhibitors in the redifferentiation of RAIrefractory DTC.

\section{Conclusion}

In conclusion, advanced DTC requires close monitoring, given the possibility of the

\section{References}

1. Haugen BR, Alexander EK, Bible $K C$, et al. 2015 American Thyroid Association Management Guidelines for adult patients with thyroid nodules and differentiated thyroid cancer: The American Thyroid Association Guidelines Task Force on thyroid nodules and differentiated thyroid cancer. Thyroid. 2016; 26(1):1-133.

https://doi.org/10.1089/thy.2015.0020

2. Brenner $\mathrm{H}$. Long-term survival rates of cancer patients achieved by the end of the 20th century: a period analysis. Lancet. 2002; 360(9340):1131-1135. https://doi.org/10.1016/S0140-6736(02)111998

3. Durante C, Haddy N, Baudin E, et al. Longterm outcome of 444 patients with distant metastases from papillary and follicular thyroid carcinoma: benefits and limits of radioiodine therapy. J Clin Endocrinol Metab. 2006; 91(8):2892-2899.

https://doi.org/10.1210/jc.2005-2838

4. Henriques de Figueiredo $\mathrm{B}$, Godbert $\mathrm{Y}$, Soubeyran I, et al. Brain metastases from thyroid carcinoma: a retrospective study of 21 patients. Thyroid. 2014; 24(2):270-276. https://doi.org/10.1089/thy.2013.0061

5. Jayarangaiah A, Sidhu G, Brown J, et al. Therapeutic options for advanced thyroid appearance of radioactive iodine resistance, most likely through the emergence of new genetic mutations in the cancer cells. In patients with RAI-refractory DTC, treatment with novel targeted systemic therapy like TKIs is justified to reduce tumor volume facilitating surgical resection and decrease perioperative morbidity but also to improve functional outcomes of RAIT and to afford prolonged progression-free survival advantage.

\section{Consent for publication}

Written informed consent was obtained from the patient for publication of this case report and accompanying images. A copy of the written consent is available for review by the Editor-in-Chief of this journal.

\section{Conflicts of interest}

The authors declare that they have no competing interests.

cancer. Int J Clin Endocrinol Metab. 2019; 5(1):26-34.

https://doi.org/10.17352/ijcem.000040

6. Stewart KE, Strachan MWJ, Srinivasan D, MacNeill M, Wall L, Nixon IJ. Tyrosine kinase inhibitor therapy in locally advanced differentiated thyroid cancer: a case report. Eur Thyroid J. 2019; 8(2):102-107. https://doi.org/10.1159/000494880

7. Szumowski $P$, Abdelrazek $S$, Iwanicka $D$, et al. Dosimetry during adjuvant ${ }^{131}$ I therapy in patients with differentiated thyroid cancerclinical implications. Sci Rep. 2021; 11(1):13930. https://doi.org/10.1038/s41598$\underline{021-93431-1}$

8. Iñiguez-Ariza NM, Bible KC, Clarke BL. Bone metastases in thyroid cancer. J Bone Oncol. 2020; 21:100282.

https://doi.org/10.1016/j.jbo.2020.100282

9. Dinneen SF, Valimaki MJ, Bergstralh EJ, Goellner JR, Gorman CA, Hay ID. Distant metastases in papillary thyroid carcinoma: 100 cases observed at one institution during 5 decades. J Clin Endocrinol Metab. 1995; 80(7):2041-2045.

https://doi.org/10.1210/jcem.80.7.7608252

10. Ikekubo K, Hino M, Ito $H$, et al. Seven cases of brain metastasis from papillary thyroid carcinoma. Kaku Igaku. 2000; 37(4):349-357. 
11. Tahmasebi FC, Farmer $P$, Powell SZ, et al. Brain metastases from papillary thyroid carcinomas. Virchows Arch. 2013; 462(4):473480. https://doi.org/10.1007/s00428-013-13944

12. Osborne JR, Kondraciuk JD, Rice SL, et al. Thyroid cancer brain metastasis: survival and genomic characteristics of a large tertiary care cohort. Clin Nucl Med. 2019; 44(7):544-549. https://doi.org/10.1097/RLU.000000000000261 $\underline{8}$

13. Saito $F$, Uruno $T$, Shibuya $H$, et al. Prognosis after brain metastasis from differentiated thyroid carcinoma. World J Surg. 2016; 40(3):574-81. https://doi.org/10.1007/s00268016-3405-5

14. Hirsch D, Gorshtein A, Robenshtok E, et al. Second radioiodine treatment: limited benefit for differentiated thyroid cancer with locoregional persistent disease. $J$ Clin Endocrinol Metab. 2018; 103(2):469-476. https://doi.org/10.1210/jc.2017-01790

15. Fullmer $T$, Cabanillas ME, Zafereo M. Novel therapeutics in radioactive iodine-resistant thyroid cancer. Front Endocrinol (Lausanne). 2021; 12:720723. https://doi.org/10.3389/fendo.2021.720723

16. Borrelli N, Panebianco $F$, Condello V, et al. Characterization of activating mutations of the MEK1 gene in papillary thyroid carcinomas. Thyroid. 2019; 29(9):1279-1285. https://doi.org/10.1089/thy.2019.0065

17. Seo GH, Cho YY, Chung JH, Kim SW. Increased risk of leukemia after radioactive iodine therapy in patients with thyroid cancer: a nationwide, population-based study in Korea. Thyroid. 2015; 25(8):927-934. https://doi.org/10.1089/thy.2014.0557

18. Alsaud A, Mohamed S, Yassin MA, Ashour A, Obeidat K, Azrieh B. Acute myeloid leukemia after low-dose radioiodine therapy for papillary thyroid carcinoma. Case Rep Oncol. 2020; 13(1):207-211.

https://doi.org/10.1159/000505686

19. Chakravarty D, Santos E, Ryder $M$, et al. Small- molecule MAPK inhibitors restore radioiodine incorporation in mouse thyroid cancers with conditional BRAF activation. $J$ Clin Invest. 2011; 121(12):4700-4711. https://doi.org/10.1172/JCl46382

20. Zhang Z, Liu D, Murugan AK, Liu Z, Xing M. Histone deacetylation of NIS promoter underlies BRAF V600E-promoted NIS silencing in thyroid cancer. Endocr Relat Cancer. 2014; 21(2):161-173. https://doi.org/10.1530/ERC13- 0399

21. Brose MS, Nutting CM, Jarzab $B$, et al. Sorafenib in radioactive iodine-refractory, locally advanced or metastatic differentiated thyroid cancer: a randomised, double-blind, phase 3 trial. Lancet. 2014; 384(9940):319328. https://doi.org/10.1016/S01406736(14)60421-9

22. Schlumberger $M$, Tahara $M$, Wirth $L J$, et al. Lenvatinib versus placebo in radioiodinerefractory thyroid cancer. $N$ Engl J Med. 2015; 372:621-630 https://doi.org/10.1056/NEJMoa1406470

23. Pitoia $F$, Jerkovich $F$. Selective use of Sorafenib in the treatment of thyroid cancer. Drug Des Devel Ther. 2016; 10:1119-1131. https://doi.org/10.2147/DDDT. S82972

24. Cabanillas ME, de Souza JA, Geyer $S$, et al. Cabozantinib as salvage therapy for patients with tyrosine kinase inhibitor-refractory differentiated thyroid cancer: results of a multicenter phase II international thyroid oncology group trial. J Clin Oncol. 2017; 35(29):3315-3321.

https://doi.org/10.1200/JCO.2017.73.0226

25. Cohen EE, Tortorici M, Kim S, Ingrosso A, Pithavala YK, Bycott P. A Phase II trial of axitinib in patients with various histologic subtypes of advanced thyroid cancer: long-term outcomes and pharmacokinetic/ pharmacodynamic analyses. Cancer Chemother Pharmacol. 2014; 74(6):1261$1270 . \quad$ https://doi.org/10.1007/s00280-0142604-8

26. Bible KC, Suman VJ, Molina JR, et al. Efficacy of pazopanib in progressive, radioiodinerefractory, metastatic differentiated thyroid cancers: results of a phase 2 consortium study. Lancet Oncol. 2010; 11(10):962-972. https://doi.org/10.1016/S1470-2045(10)70203$\underline{5}$

27. Yansong L, Yang $H$, Ding $Y$, et al. Donafenib in progressive locally advanced or metastatic radioactive iodine-refractory differentiated thyroid cancer: results of a randomized, multicenter, phase II trial. Thyroid. 2020; 31(4):607-615. https://doi.org/10.1089/thy.2020.0235

28. Jin N, Jiang T, Rosen DM, Nelkin BD, Ball DW. Synergistic action of a RAF inhibitor and a dual $\mathrm{PI} 3 \mathrm{~K} / \mathrm{mTOR}$ inhibitor in thyroid cancer. Clin Cancer Res. 2011; 17(20):6482-6489. https://doi.org/10.1158/1078-0432.ccr-11-0933

29. Tsumagari $K$, Abd Elmageed $Z Y$, Sholl $A B$, et al. Bortezomib sensitizes thyroid cancer to BRAF inhibitor in vitro and in vivo. Endocr Relat Cancer. 2017; 25(1):99-109. https://doi.org/10.1530/erc-17-0182

30. Kebebew E, Ghosh C, Kumar S, et al. A combinatorial strategy for targeting BRAF V600E mutant cancers with BRAF V600E 
inhibitor (PLX4720) and tyrosine kinase inhibitor (ponatinib). Clin Cancer Res. 2020; 26:2022-2036. https://doi.org/10.1158/10780432.ccr-19-1606

31. Ho AL, Grewal RK, Leboeuf $R$, et al. Selumetinib-enhanced radioiodine uptake in advanced thyroid cancer. N Engl J Med. 2013; 368(7):623-632.

https://doi.org/10.1056/nejmoa1209288

32. Rothenberg SM, McFadden DG, Palmer EL, Daniels GH, Wirth LJ. Redifferentiation of iodine-refractory BRAF V600E-mutant metastatic papillary thyroid cancer with dabrafenib. Clin Cancer Res. 2014; 21(5):1028-1035. https://doi.org/10.1158/10780432.ccr-14-2915

33. Dunn LA, Sherman EJ. Baxi SS, et al. J Clin Endocrinol Metab. 2019; 104(5):1417-1428. https://doi.org/10.1210/jc.2018-01478

34. Jaber T, Waguespack SG, Cabanillas ME, et al. Targeted therapy in advanced thyroid cancer to resensitize tumors to radioactive iodine. J Clin Endocrinol Metab. 2018; 103(10): 3698-3705. https://doi.org/10.1210/jc.2018$\underline{00612}$ 